\title{
Health Information Seeking, Receipt, and Use in Diabetes Self-Management
}

Daniel R. Longo, $S c D^{1}$

Shari L. Schubert, $B A^{2}$

Barbara A. Wright, MLS, AHIP,1,3

Joseph LeMaster, MD, MPH

Casey D. Williams, $M D^{2}$

Jobn N. Clore, MD

'Department of Family Medicine, Virginia Commonwealth University School of Medicine, West Hospital, Richmond, Virginia

${ }^{2}$ Department of Family and Community Medicine, School of Medicine, University of Missouri-Columbia, Columbia, Missour

${ }^{3}$ Tompkins-McCaw Library for the Health Sciences, VCU Libraries, Virginia Commonwealth University, Richmond, Virginia

${ }^{4}$ Department of Internal Medicine, Division of Endocrinology and Metabolism, Medical College of Virginia/Virginia Commonwealth University, Richmond, Virginia

Conflicts of interest: none reported

\section{CORRESPONDING AUTHOR}

Daniel R. Longo, ScD

Department of Family Medicine

Virginia Commonwealth University School of Medicine

West Hospital, 14th Floor

PO Box 980251

Richmond, VA 23298-0251

drlongo@vcu.edu

\begin{abstract}
PURPOSE Diabetes self-management is essential for diabetes control, yet little is known about patient preferences for sources of health information or about the extent to which information is sought directly or received passively through various media sources. The aim of this qualitative study was to identify how individuals with diabetes seek and use health care information.
\end{abstract}

METHODS Using a health information model to guide our research, we conducted 9 focus groups with 46 adults with a diagnosis of diabetes and then analyzed the transcripts and notes from these focus groups.

RESULTS Five themes emerged: (1) passive receipt of health information about diabetes is an important aspect of health information behavior; (2) patients weave their own information web depending on their disease trajectory; (3) patients' personal relationships help them understand and use this information; (4) a relationship with a health care professional is needed to cope with complicated and sometimes conflicting information; and (5) health literacy makes a difference in patients' ability to understand and use information.

CONCLUSIONS Patients make decisions about diabetes self-management depending on their current needs, seeking and incorporating diverse information sources not traditionally viewed as providing health information. Based on our findings, we have developed a new health information model that reflects both the nonlinear nature of health information-seeking behavior and the interplay of both active information seeking and passive receipt of information.

Ann Fam Med 2010;8:334-340. doi:10.1370/afm.1115.

\section{INTRODUCTION}

$\mathrm{D}$ iabetes mellitus, a common and rapidly increasing chronic disease, affects approximately 23.6 million Americans. ${ }^{1}$ Diabetes self-management is "a critical element of care" 2 that must be supported by a lifelong education process. The synergistic effects of the consumer movement and the explosion of readily available health information may lead to information overload, and this information can be conflicting and confusing.

The field of communication has a long tradition of studying health information-seeking behavior (HISB), which focuses on how people seek and manage information about their health. Concepts shown to be important to information seeking can be grouped into 3 areas: factors related to the source of information, such as source credibility ${ }^{3.7}$; factors regarding the message itself, such as the clarity or ambiguity of the argument or information; and characteristics of the individual seeking the information, such as perceived task importance, ${ }^{4,8,9}$ Few studies comprehensively examine patient approaches to HISB and diabetes self-management. ${ }^{4,8-11}$ Additionally, the current literature lacks patients' stories that provide a context or narrative for understanding how patients receive or seek information. 
Most HISB studies investigate what we refer to as active information seeking, that is, they examine how and why patients try to acquire specific information that they expect to be useful for their intended purposes. There is a second aspect of HISB, however, that we refer to as passive receipt of health information, by which patients acquire information unintentionally as a by-product of daily life activities, such as television viewing or newspaper reading. Both contextual and personal patient characteristics influence their health information-seeking behavior, which in turn influences active information seeking and passive information receipt, as well as their interaction. Finally, these variables and their interaction influence patient/consumer outcomes.

In 2005 we developed a conceptual model of health information (Health Information Model) based on active information seeking and passive receipt of health information that explicitly acknowledges the interplay among the 3 methods of gathering information. ${ }^{12-14}$ Since then, this model has been used successfully in other studies. ${ }^{15-20}$ Although the Health Information Model was originally developed for cancer patients, it can be adapted for patients with chronic diseases, such as diabetes, with only minor modifications.

We conducted a qualitative study using focus groups to learn how individuals with diabetes seek and use health care information and to examine the roles of physicians and others in interpersonal relationships as patients maneuver through the information they both actively seek and passively receive. We used the Health Information Model to identify how individuals with diabetes seek and use health care information.

\section{METHODS}

Participants were recruited from among patients who received diabetes care from 2 clinics in a Midwestern city. After eligible patients were identified and contacted, a research nurse made follow-up contact to explain the study, obtain informed consent, and schedule the focus groups. To achieve the broadest possible range of insight, participants were recruited to ensure diversity in age, race, and sex typical of a family medicine practice.

Focus group participants completed a brief printed questionnaire (Supplemental Appendix 1, available at

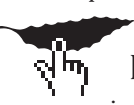

http://annfammed.org/cgi/content/full/8/4/334/

DC1) eliciting demographic characteristics and information about their experience with diabetes. An open-ended item asked them to list the specific diabetes information resources they used.

An experienced moderator led the focus groups, using broad-based questions to explore how patients obtained information about diabetes that they considered useful and reliable. Two observers took notes during the group sessions. A focus group guide (Supplemental Appendix 2, available at http:// annfammed.org/cgi/content/full/8/4/334/DC1) was used to ensure consistency of procedures, questions, and discussion topics. The guide was based on the methods described by McNamara ${ }^{21}$ and our original Health Information Model. ${ }^{12}$ Included were probes and prompts to stimulate discussion, provide follow-up lines of inquiry, clarify topics, and stimulate further focused discussion. Sessions were audio-recorded, and detailed notes were taken.

\section{Analysis}

We analyzed the transcripts, notes, and open-ended questionnaire responses using NUD*IST 6 software (QSR International Inc, Cambridge, Massachusetts), with the focus groups as the unit of analysis. Using an open-template approach, ${ }^{22}$ we established codes for the core questions in the focus group guide. We then coded the transcripts and notes so we could identify active information-seeking and passive informationreceiving behavior, how patients used information in diabetes self-management, and their information sources and use.

Using a collaborative process ${ }_{,}{ }^{23}$ investigators worked with the data independently and then discussed the findings. Through this process and several iterations of coding, reading, and discussing data, we refined our understanding of template-driven themes and identified emergent themes, which were then incorporated into the template.

\section{RESULTS}

Among the eligible patients 46 agreed to participate in the study, completed the questionnaire, and attended the focus groups. In Table 1 are displayed the demographic characteristics of the participants. Table 2 is a list of the sources of information reported by the participants.

During the 9 scheduled focus group meetings, participants identified a diverse and comprehensive range of information sources, including not only traditional health information materials but also information from the Internet, television, and newspaper, as well as friends and health care professionals. This diversity reflects the nature of diabetes, which touches all aspects of daily living, including relationships with family and friends, medications, cooking and portion control, exercise, and food shopping.

Our analyses of data from the open-ended questions on the questionnaire and the focus group discus- 
Table 1. Demographic Characteristics of Focus Group Participants $(n=46)$

\begin{tabular}{|c|c|}
\hline Characteristic & Value \\
\hline Age, average (range), y & $61(48-77)$ \\
\hline \multicolumn{2}{|l|}{ Time since diagnosis, No. (\%) } \\
\hline$<1$ y & $3(6.5)$ \\
\hline$\geq 1$ y but $<2$ y & $9(19.6)$ \\
\hline$\geq 2$ y but $<3$ y & $5(10.9)$ \\
\hline$\geq 3$ y but $<4$ y & $2(4.3)$ \\
\hline$\geq 4$ y but $<5$ y & $1(2.2)$ \\
\hline$\geq 5$ & $26(56.5)$ \\
\hline \multicolumn{2}{|l|}{ Type of diabetes (self-described), No. (\%) } \\
\hline Type 1 & $1(2.2)$ \\
\hline Type 2 & $34(75.6)$ \\
\hline Don't know & $10(22.2)$ \\
\hline Take insulin? (yes answers) & $12(26.7)$ \\
\hline Take oral medication? (yes answers) & $36(87.8)$ \\
\hline \multicolumn{2}{|l|}{$\begin{array}{l}\text { Received initial education... (yes answers; catego- } \\
\text { ries are not mutually exclusive), No. (\%) }\end{array}$} \\
\hline From doctor? & $30(68.2)$ \\
\hline From nurse? & $20(51.3)$ \\
\hline From dietician? & $25(65.8)$ \\
\hline From diabetes educator & $22(59.5)$ \\
\hline Sought additional information? (yes answers) & $24(54.5)$ \\
\hline \multicolumn{2}{|l|}{ Sex, No. $(\%)$} \\
\hline Male & $16(35.6)$ \\
\hline Female & $29(64.4)$ \\
\hline \multicolumn{2}{|l|}{ Ethnic background, No. (\%) } \\
\hline African American/black & $10(21.7)$ \\
\hline American Indian/Eskimo/Aleut & $0(0.0)$ \\
\hline Asian/Pacific Islander & $1(2.2)$ \\
\hline White & $32(69.6)$ \\
\hline Latino/Hispanic & $0(0.0)$ \\
\hline Other & $3(6.5)$ \\
\hline \multicolumn{2}{|l|}{ Marital status, No. (\%) } \\
\hline Married/living as married & $26(56.5)$ \\
\hline Divorced & $6(13.0)$ \\
\hline Separated & $2(4.3)$ \\
\hline Widowed & $7(15.2)$ \\
\hline Single, never married & $5(10.9)$ \\
\hline \multicolumn{2}{|l|}{ Highest level of education, No. (\%) } \\
\hline 8 th grade or less & $2(4.3)$ \\
\hline Some high school (grade 9-12) & $3(6.5)$ \\
\hline High school or general equivalency diploma & $12(26.1)$ \\
\hline Vocational school or some college & $12(26.1)$ \\
\hline College degree & 9 (19.6) \\
\hline Professional or graduate school experience & $8(17.4)$ \\
\hline \multicolumn{2}{|l|}{ Estimated annual household income, No. (\%) } \\
\hline$<\$ 15,000$ & $17(38.6)$ \\
\hline$\$ 15,000-\$ 29,999$ & $8(18.2)$ \\
\hline$\$ 30,000-\$ 49,999$ & $7(15.9)$ \\
\hline$\$ 50,000-\$ 74,999$ & $7(15.9)$ \\
\hline$\geq \$ 75,000$ & $5(11.4)$ \\
\hline Have Internet access? (yes answers) & $35(76.1)$ \\
\hline
\end{tabular}

Table 2. Information Sources Cited by Focus Group Participants

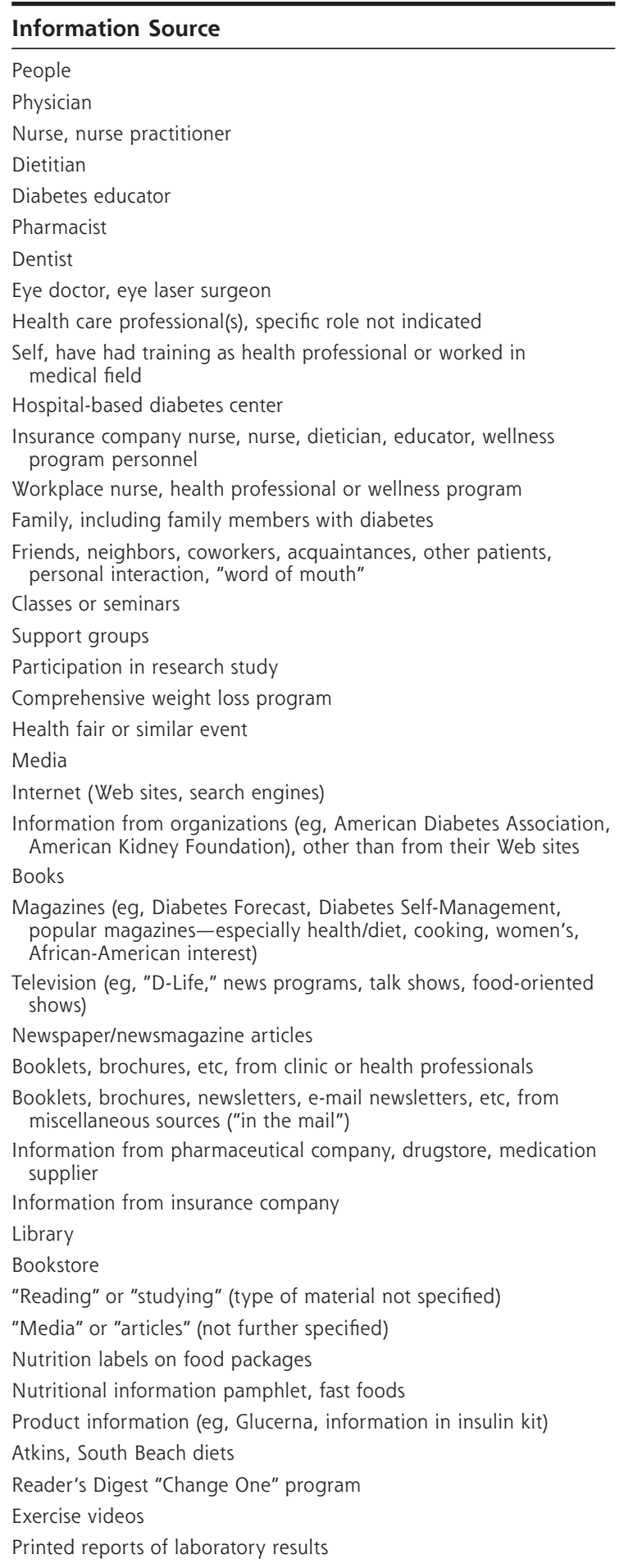

sions led to the emergence of the 5 themes that fill important gaps in our understanding of health information seeking, receipt, and use in diabetes. Identification of these themes helped us to modify our initial con- 
ceptual model (Figure 1) and identify hypotheses for further exploration.

\section{Patients Passively Receive Diabetes Health Information}

Many focus group participants reported that the media, such as the newspaper and television, played an inadvertent role in providing information on diabetes. One individual reported, "Well, you know, a lot of times you do pick up the newspaper, and there's so much information about health overall, nowadays, that you pick up something periodically on diabetes." Others mentioned television talk shows, such as The Oprab Winfrey Show. One participant, in speaking about her talk show television-viewing habits, remarked, "In fact it's a lot of different times even on those stations they bring up about [sic] diabetes."

These examples illustrate the concept of passive receipt of information ${ }^{12}$; that is, individuals who may not be actively engaged in what traditionally has been

\section{Figure 1. Longo Health Information Model: information seeking, passive receipt, and use.}

Variables Influencing Patient/Consumer Information-Seeking Behaviors Behavior and Information Use

\section{Contextual}

Health status, health care structure, delivery of care, information environment, information seeking for self, family member, or friend at risk or with current medical problem, interpersonal social supports, networks

\section{Personal}

Demographic factors, socioeconomic factors, health history, genetics, stress, education, culture, language, attitudes, behaviors, current health status, cognitive ability, interpersonal communication motives

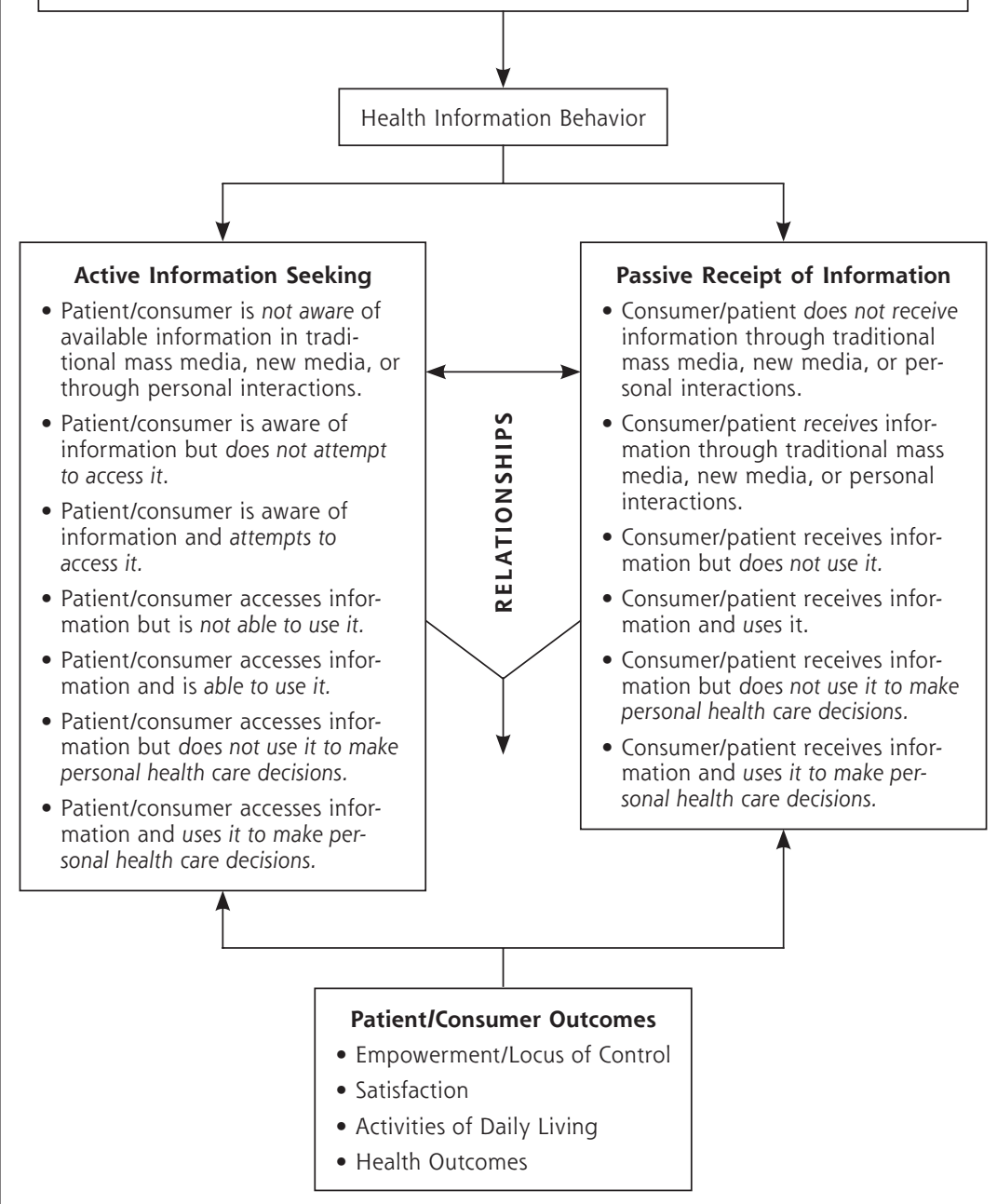

Adapted with permission from Blackwell Publishing. The figure was originally published in Longo, et al. ${ }^{12}$ called information-seeking behavior come across relevant health information about their diabetes during the course of such daily activities as surfing television channels or reading newspapers or magazines.

\section{Patients Actively Weave Their Own Information Web}

Participants reported using the Internet as an important information source for managing their diabetes. They identified diabetes and health-related sites, such as diabetes.com, WebMD, American Diabetes Association, and Mayo Clinic, as well as many non-diabetes-specific Web sites devoted to cooking, exercise, and stress reduction. Participants also frequently mentioned traditional print media, including books, brochures, and magazines, which suggests that the electronic media have not displaced traditional media as a source of information. They also referenced a variety of cookbooks with low-fat and low-carbohydrate recipes, recipes from relatives and friends, and exercise videos. Most participants also relied heavily on both verbal and printed information provided by physicians, nurse, and dietitians.

Some participants, even years after diabetes was diagnosed, expressed the need for periodic reeducation as they realized how much there is to learn, encountered confusing or conflicting information, or discovered that information changes over time. 
Patients edited their web of information with time, adding and deleting as gained experience. One participant stated,

I think initially I...just wanted information, all kinds of information. I wanted to be bombarded with information, and I think I've become much more selective now because I realize there is a lot of information out there, but I realize that it truly is up to me.

This statement elicited nods of agreement from the other participants

Patients who managed diabetes for longer periods developed a commonsense standard they wanted the information to satisfy to be considered credible. They reported that they could determine credible information based on their accumulated knowledge. One participant explained to others who felt overwhelmed: "The more you read, and educate yourself, then the better. You're in a better position to make good judgments as far as what to do."

Thus, it appears that each patient weaves a unique web of information beginning with the initial diagnosis of diabetes. The substance of this web evolves in response to life experiences, health status changes, and other important events.

\section{Patients' Relationships Help Them Understand and Use Information}

Relatives and friends were among the most frequently cited sources of information, especially in families with a history of diabetes. Participants related how their prior experiences with parents, spouses, siblings, or other relatives with diabetes prepared them to plan meals and cook appropriately, even before their own diagnosis. One woman said, "My whole family is diabetic, so we talk a lot!" Another woman pointed out, "My husband was diabetic for years, so I had first-hand knowledge because I had to cook for him. So by the time it got to me, I really understood what it was and what it was about."

Relatives and friends also became a sounding board to discuss the disease and its management, as well as the sometimes conflicting information provided by health professionals and the media.

If I can't get that information from a doctor or a dietician or someplace else, I'm going to keep after it until I resolve in my mind how I can make something work for me. If I don't believe them, or it's not working for me, I will challenge them. And if I don't get the answers I want, and it's not working for me, then I go on to somebody else. I just discard them, and I'm on to somebody else, and I'm going to keep after it until I find out what's going to work for me.

Relationships may be nontraditional, such as those that develop exclusively by telephone. One participant discussed the personalized care and attention received from an insurance company disease management nurse

I also have, the insurance company has a wellness program. And I've got this nurse that calls me, maybe 6 months, and we have about a 30 - to 45 -minute phone conversation... And they're very good about personalizing it.

\section{Health Care Professionals Help to Understand and Manage Information}

Although the patients' information web is essential, it is not sufficient to help patients understand their health information. Many expressed that information overload had been a hindrance in their initial postdiagnosis self-management efforts, and for some the volume and complexity of the information had a paralyzing effect. This reaction was true for information provided in traditional diabetes education and for diabetes-related Internet information. Participants often mentioned they brought the information they found on the Internet or in other sources to their physician, dietician, nurse practitioner, or other clinician for confirmation, a critical function of health care professionals during patient encounters. One individual remarked,

Well, I'll copy off a lot of things, but before I'll use it, I'll run it by my MD. And when you see these different things that say taking Actose helps, all these ads that say by taking this specific drug that it will help you. I go to my doctor and tell him what I have seen or show him what I have seen and he won't exactly agree with it, doesn't change it!"

Generally, health professionals were among the most frequently mentioned sources of information, both immediately after the diagnosis and over a lifetime of treatment. One participant described the nurse practitioner and doctor as "a wealth of information." Another participant related, "I think my best source was the nurse. Bless her soul. She just works hard at treating diabetes." Another woman added, "I love the doctor and nurse of the diabetes center, the dietician, and the nurse educator. I know I can trust what they're telling me." The importance of professional support is reflected by the following statement: "I rely on people who have the knowledge, such as the dietician and the health educator in diabetes, or whatever it might be."

Nurse practitioners, diabetes educators, and dietitians were credited in all groups as the most useful and informative sources. Participants noted these clinicians spend more time with patients in one-on-one education and personalized feedback.

I just feel just wonderful.... No matter what I've asked, or no matter what, it's answered, or I'm taken to wherever it is.... I can call her anytime, and she knows, or she'll find out. I went to the med center, to the dietician and if I ran into problems, 
she gave me a number I could call her direct. And she helped me with my diet, if I needed that, I still have my book that I go through.... I have the book. But right now I'm very happy with where I'm at. They make me feel very comfortable.

\section{Health Literacy Makes a Difference}

Across groups, participants consistently voiced a preference for information that is immediately accessible and easy to understand. As one participant reported:

I also think that for people that are newly diagnosed, even adults, to give real basic, childlike information, [like] 'this is what insulin in your body does."'

This need for clear, simple communication was true for participants with both higher and lower levels of education. One librarian stated:

And I know that sounds funny, you know, I am a well educated adult, but still it helps me to have that very basic level information. I can read over and over and over and it just doesn't seem to make any sense.... It is a clue to me that there is some kind of information there, but it is beyond my comprehension at that point in time. Now maybe a week later I can read the same thing and it makes sense, but there are times that you can read something, and I have... read it and it didn't make sense, so I took it to my doctor or the nurse practitioner.

Although functional health literacy was not quantitatively measured for participants, it became apparent as an issue in self-management. "For a lot of people, it's difficult.... [It] just seems like some of this diabetic information ought to be written by laymen, or interpreted or something." This basic level of understanding serves as a filter through which participants view diabetes information.

\section{DISCUSSION}

That diabetes affects all aspects of the study participants' life was reflected in the diversity and consistency of information participants reported seeking and receiving. They sought medical- and disease-specific information, as well as information on diet, exercise, and stress management. They relied on their relationships with friends and family and their clinicians to reinforce and confirm the information they gathered. The themes identified encompass the full spectrum of activities of daily living and the centrality of diabetes self-management concerns.

Patients looked for what they perceived to be the credible sources for their unique needs as they wove their ongoing web of information. They looked for information that made sense based on their own knowledge and their experience of self-management, and they looked to their clinicians to reinforce this infor- mation. They spoke of how information use changed over time, and there were instances when they sought and were receptive to information that they used on a regular basis. At other times they relapsed in their information seeking and use and were almost in denial about their diabetes. One may conclude that the web of information patients weave requires the right information at the right time, and life events clearly have an impact on what that right time may be.

Despite the power of the Internet, patients reported they relied more on traditional sources of information, most particularly nurse practitioners, dietitians, and diabetes educators. Physicians, too, played a major role in diagnosis and treatment, as well as in addressing conflicting information. Patients further reported they relied on family and friends. In this way, relationships helped them understand and use their web of information. The ebb and flow of active seeking and passive receipt of information reflect the chronic nature of diabetes, which can endure over a lifetime.

Our findings suggest a conceptual model of HISB that is more dynamic than many of those proposed in current literature. Patients do not proceed toward behavior change in a linear fashion; rather, they make decisions regarding self-management depending on current needs, seeking and incorporating information to help them do what seems important at the moment. Based on our study findings, we have reconfigured the original Health Information Model to explicitly reflect this nonlinear interplay of both active information-seeking behavior and passive information receipt, as well as the important role relationships play as the patients incorporate the information that works for them (Figure 1). Our revised HISB model goes beyond traditional theories of information-seeking behavior.

Although the study was conducted in one Midwestern city, its qualitative design enabled a broad range of responses. The sample size was large enough to reach saturation, which allowed us to be confident that we had a comprehensive information source list. Although participants were socioeconomically and ethnically diverse, and we are reasonably certain that the responses reflect the views and background of a diverse population, regional differences in information-seeking and information-receiving behavior cannot be determined.

We identified some areas to consider when developing hypotheses for future research, including (1) the relationship between improved self-management and various types of information, (2) issues of health literacy as they affect information use, (3) how self-management changes with time and its impact on information use, and (4) the effect of information on outcomes that matter to patients in the short and long term. 
Although the goal of empowering and engaging diabetic patients to be informed, proactive, cost-conscious health care consumers may be fostered by innovations such as the Consumer Driven Health Care model, McNutt cautions that "the view of medical decision making with the patient as the pilot and the physician as the navigator is not yet common in medical care." ${ }^{14}$ Future research must ask: What are the potential downsides or unintended consequences of patient-driven health information acquisition without appropriate professional critique and guidance? We contend that patients still want physician help and guidance.

To read or post commentaries in response to this article, see it online at http://www.annfammed.org/cgi/content/full/8/4/334.

Key words: Diabetes mellitus; self-management; education; patient

Submitted April 1, 2009; submitted, revised, November 11, 2009; accepted November 25, 2009.

Author contribution: Dr Longo had full access to all the data in the study and takes responsibility for the integrity of the data and the accuracy of the data analysis.

Funding support: Funding for this study was provided through a research development grant from the Department of Family and Community Medicine at the University of Missouri-Columbia. The department did not control the design and conduct of the study; collection, management, analysis, and interpretation of the data; or preparation, review, and approval of the manuscript.

Acknowledgments: William Miller helped with the qualitative methods used in this study, Julie Brandt was a focus group facilitator, and Susan E. Meadows and Susan Elliott of the University of Missouri-Columbia (UMC) Family Medicine Library assisted with the literature search.

\section{References}

1. Partnership to Fight Chronic Disease. United States Workplace Wellness Alliance. Almanac of Chronic Disease, 2009 Edition: The Impact of Chronic Disease on U.S. Health and Prosperity: A Collection of Statistics and Commentary. Washington, DC: Partnership to Fight Chronic Disease: US Workplace Wellness Alliance; 2009.

2. Funnell MM, Brown TL, Childs BP, et al. National standards for diabetes self-management education. Diabetes Care. 2009;32(Suppl 1): s87-s94.

3. Giffin K. The contribution of studies of source credibility to a theory of interpersonal trust in the communication process. Psychol Bull. 1967;68(2):104-120

4. Hovland $\mathrm{Cl}$, Weiss W. The influence of source credibility on communication effectiveness. Public Opin Q. 1951;15:635-650.

5. Graham EE, Barbato CA, Perse EM. The interpersonal communication motives model. Commun Q. 1993;41(2):172-186.
6. Anderson CM, Martin MM. Communication motives of assertive and responsive communicators. Commun Res Rep. 1995;12:186-191.

7. Renders CM, Valk GD, Griffin SJ, Wagner EH, Eijk Van JT, Assendelft WJ. Interventions to improve the management of diabetes in primary care, outpatient, and community settings: a systematic review. Diabetes Care. 2001;24(10):1821-1833.

8. Chaiken S, Maheswaran D. Heuristic processing can bias systematic processing: effects of source credibility, argument ambiguity, and task importance on attitude judgment. J Pers Soc Psychol. 1994;66(3):460-473.

9. Wilson TD. Information behaviour: an interdisciplinary perspective. Inf Process Manage. 1997;33(4):551-572.

10. Dutta-Bergman MJ. Primary sources of health information: comparisons in the domain of health attitudes, health cognitions, and health behaviors. Health Commun. 2004;16(3):273-288.

11. Dutta-Bergman MJ. Media use theory and internet use for health care. In: Murero M, Rice RE, eds. The Internet and Health Care: Theory, Research, and Practice. Mahwah, NJ.: Lawrence Erlbaum Associates; 2006:83-103.

12. Longo DR. Understanding health information, communication, and information seeking of patients and consumers: a comprehensive and integrated model. Health Expect. 2005;8(3):189-194.

13. Longo DR, Ge B, Greiner A, et al. Understanding breast-cancer patients' perceptions: Health information-seeking behaviour and passive information receipt. J Comm Healthcare. 2009;2(2):184-206.

14. Wright K. Social support within on on-line cancer community: An assessment of emotional support, perceptions of advantages and disadvantages, and motives for using the community from a communication perspective. J Appl Commun Res. 2002;30(3):195-209.

15. Lambert SD, Loiselle CG. Health information seeking behavior. Qual Health Res. 2007;17(8):1006-1019.

16. Dean AJ, Witham M, McGuire T. Predictors of safety-related enquiries about psychotropic medication in young people and families accessing a medicines information service. J Child Adolesc Psychopharmacol. 2009;19(2):179-185.

17. Edwards M, Davies M, Edwards A. What are the external influences on information exchange and shared decision-making in healthcare consultations: a meta-synthesis of the literature. Patient Educ Couns. 2009;75(1):37-52.

18. Ishikawa $\mathrm{H}$, Yano E. Patient health literacy and participation in the health-care process. Health Expect. 2008;11(2):113-122.

19. O'Leary KA, Estabrooks CA, Olson K, Cumming C. Information acquisition for women facing surgical treatment for breast cancer: influencing factors and selected outcomes. Patient Educ Couns. 2007;69(1-3):5-19.

20. Hu W, Grbich C, Kemp A. Parental food allergy information needs: a qualitative study. Arch Dis Child. 2007;92(9):771-775.

21. McNamara C. Basics of conducting focus groups. http://www.managementhelp.org/evaluatn/focusgrp.htm. Accessed Jun 16, 2009.

22. Crabtree BF, Miller WL. Doing Qualitative Research. 2nd ed. Thousand Oaks, CA: Sage Publications; 1999.

23. Paulus T, Woodside M, Ziegler M. Extending the conversation: qualitative research as dialogic collaborative process. Qual Rep. 2008;13(2):226-243.

24. McNutt RA. Shared medical decision making: problems, process, progress. JAMA. 2004;292(20):2516-2518. 